\title{
RHOMBOHEDRAL IRON TRIFLUORIDE WITH A HIERARCHIZED MACROPOROUS/MESOPOROUS TEXTURE FROM GASEOUS FLUORINATION OF IRON DISILICIDE

\author{
Diane Delbègue ${ }^{(1)(2)}$, Katia Guérin ${ }^{(1)(2)}$, Barbara Laik ${ }^{(3)}$, Jean-Pierre Pereira-Ramos ${ }^{(3)}$, Moulay-Tahar \\ Sougrati $^{(4)}$, Céline Cénac-Morthe ${ }^{(5)}$ \\ (1) Université Clermont Auvergne, Université Blaise Pascal, Institut de Chimie de Clermont-Ferrand, BP 10448, F- \\ 63000 CLERMONT-FERRAND, France, Diane.Delbegue@univ-bpclermont.fr \\ ${ }^{(2)}$ CNRS, UMR 6296, ICCF, F-63171 Aubière, France \\ (3) Université Paris Est Créteil, Institut de Chimie et des Matériaux Paris-Est, UMR CNRS 7182 Thiais, France \\ (4) Université Montpellier II, Institut Charles Gerhardt de Montpellier, UMR CNRS 5253 Montpellier, France \\ ${ }^{(5)}$ Centre National d'Etudes Spatiales, Toulouse, France, Celine.Cenac-Morthe@cnes.fr
}

\begin{abstract}
Stable low temperature rhombohedral iron trifluoride has been obtained by the fluorination under the pure fluorine gas of iron disilicide. The combination of both unusual fluorination process and precursor avoids to get unhydrated crystalline $\mathrm{FeF}_{3}$ particles and allows the formation of hierarchized channels of mesoporous/macroporous texture favorable for lithium diffusion. The fluorination mechanism proceeds by temperature steps from the formation, for a fluorination temperature below $200{ }^{\circ} \mathrm{C}$, of an amorphous phase and an intermediate iron difluoride identified mainly by ${ }^{57} \mathrm{Fe}$ Mössbauer spectroscopy before getting, as soon as a fluorination temperature of $260{ }^{\circ} \mathrm{C}$ is reached, the rhombohedral $\mathrm{FeF}_{3}$. Both amorphous and crystallized samples display good ability for electrochemical process when used as cathode in lithium-ion battery. The low diameter of rhombohedral structure channels is balanced by an appropriate mesoporous texture and a capacity of $225 \mathrm{mAh}^{-1} \mathrm{~g}^{-1}$ after 5 cycles for a discharge cut-off of 2.5 $\mathrm{V}$ vs. $\mathrm{Li}^{+} / \mathrm{Li}$ at a current density of $\mathrm{C} / 20$ has been obtained and stabilized at $95 \mathrm{mAh} \cdot \mathrm{g}^{-1}$ after 116 cycles.
\end{abstract}

\section{INTRODUCTION}

Recently, Li-storage batteries have drawn tremendous attention due to their large potential market for electric vehicles and electronic consumables and devices. To realize satisfactory power and energy densities, new cathode materials must be explored [1-3]. Conversion reactions which imply the full reduction by lithium of a compound containing a metal at a high oxidation state into metal are promising reactions for designing high energy density batteries because of the large electron exchange during the electrochemical process. In order to insure high output voltage, only metal halides, for which the ionicity of the bonding is important, are good candidates and among the metal halides, only the metal fluorides do not dissolve into the electrolyte [4, 5]. Most of the researches on metal fluorides/Li batteries were devoted to surpass the insulator behavior of fluorides. Many attempts have been then dedicated to decreasing the particle size of such materials and to increase their conductivity by high energy ball-milling them with conductive carbon [6] or focusing on hydrated phases, because of the presence of water favoring the ionic conductivity [7].

Iron trifluoride has attracted substantial interest due to its electromotive force value of $3.2 \mathrm{~V}$ and a large theoretical capacity of $711 \mathrm{mAh} \cdot \mathrm{g}^{-1}$ for a redox process of three exchanged electrons [8], [9]. This capacity value is larger from the practical capacity obtained for the operational cathode materials of secondary batteries made of $\mathrm{LiFePO}_{4}$ or $\mathrm{LiCoO}_{2}$. Three electron process of metal fluorides results from two types of redox mechanism: a first one which proceeds at high potential and is due to an insertion mechanism, the second one which proceeds at lower potential and is due to a conversion mechanism. Looking at the only insertion mechanism into iron trifluorides leads to a theoretical capacity of $237 \mathrm{mAh} \cdot \mathrm{g}^{-1}$ larger than the practical 170 mAh. $\mathrm{g}^{-1}$ of today's cathode materials.

Iron trifluoride crystallizes into three anhydrous polymorphs and two amorphous phases [10]. The three polymorphs known are the rhombohedral form which is the stable high temperature phase denoted $\mathrm{r}-\mathrm{FeF}_{3}$, the orthorhombic hexagonal tungsten bronze phase HTB$\mathrm{FeF}_{3}$ and the cubic pyrochlore structure $\mathrm{Pyr}-\mathrm{FeF}_{3}$ [11]. Many hydrated phases also exist, such as HTB$\mathrm{FeF}_{3} \cdot 0.33 \mathrm{H}_{2} \mathrm{O}$ and tetragonal $\mathrm{FeF}_{3} \cdot 3 \mathrm{H}_{2} \mathrm{O}$ [12],[13]. Most of the electrochemical properties in lithium batteries of $\mathrm{FeF}_{3}$ have been obtained for such hydrated phases because iron fluorides are mainly synthesized through aqueous solution-based methods [14-17]. For dehydrated phase, the highest performance reported thus far has been obtained by Myung et al. [18] with a capacity as high as $224 \mathrm{mAh} \cdot \mathrm{g}^{-1}(1.5-4.5 \mathrm{~V})$ at $\mathrm{C} / 10$ rate with capacity retention of $71 \%$ after 100 cycles for a r$\mathrm{FeF}_{3}$ obtained via the evaporation method at $400^{\circ} \mathrm{C}$ under argon of $\mathrm{FeF}_{3} \cdot 3 \mathrm{H}_{2} \mathrm{O}$. In spite of their better performances, dehydrated phases are little studied, maybe because of the high temperature needed to get them. Indeed, for example, to obtain rhombohedral phase, temperatures higher than $400^{\circ} \mathrm{C}$ are needed [19] and lead to huge particle sizes not favorable for electrochemical purpose. 
In this work, the fluorination under pure gaseous fluorine at low temperature has been applied on $\mathrm{FeSi}_{2}$. The resulting materials have been characterized depending on their structure by X-ray diffraction, Raman and ${ }^{57} \mathrm{Fe}$ Mössbauer spectroscopies and their texture by Scanning Electron Microscopy SEM and nitrogen adsorption isotherms. Finally, a preliminary electrochemical study has been performed in lithium batteries.

\section{RESULTS}

$\mathrm{FeSi}_{2}$ has been fluorinated under a flux of pure gaseous fluorine at various temperatures up to 350 ${ }^{\circ} \mathrm{C}$. $\mathrm{FeSi}_{2}$ present two phases: $\alpha-\mathrm{FeSi}_{2}$ and $\beta-\mathrm{FeSi}_{2}$. X-ray diffraction, Raman and ${ }^{57} \mathrm{Fe}$ Mössbauer spectroscopies show that the synthesis involves

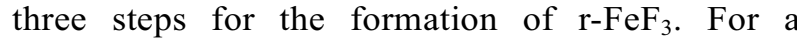
fluorination temperature of $150{ }^{\circ} \mathrm{C}, \alpha-\mathrm{FeSi}_{2}$ is preserved and $\beta-\mathrm{FeSi}_{2}$ is converted into $\mathrm{FeF}_{2}$. At $200{ }^{\circ} \mathrm{C}, \alpha-\mathrm{FeSi}_{2}$ and $\mathrm{FeF}_{2}$ are totally converted into amorphous $\mathrm{FeF}_{3}$. Finally for a temperature higher than $260{ }^{\circ} \mathrm{C}$, this amorphous $\mathrm{FeF}_{3}$ turns into $\mathrm{r}-\mathrm{FeF}_{3}$. The Fe-F bonding and their structural organization are key points for electrochemical purpose, but the texture is another strategic point which is often not clearly characterized. We have chosen to characterize in depth the texture evolution upon increase of the fluorination temperature. Indeed, morphology and texture as well as physicalchemical properties including the surface behavior of crystalline $\mathrm{FeF}_{3}$ can be assumed to be different from that of amorphous $\mathrm{FeF}_{3}$ obtained from the low temperature fluorination.

According to IUPAC classifications, the nitrogen adsorption/desorption measurements show type IV isotherms, indicating mesoporous morphology of fluoride compounds with the presence of a hysteresis loop. The shape of the hysteresis loop and the steep desorption branch classify it as of the $\mathrm{H}_{2}$ type for the lowest fluorination temperatures. This occurs for assemblies of tubular capillaries open at both ends [20]. The dimensions responsible for the adsorption branch of the isotherm are heterogeneously distributed and the dimensions responsible for desorption are of equal size. For a fluorination temperature of $350{ }^{\circ} \mathrm{C}, \mathrm{H}_{2}$ type turns into an $\mathrm{H}_{3}$ type with an adsorption branch steeper at saturation pressure. This occurs for assemblies of capillaries with slit shapes or with very wide bodies and a narrow, short neck. It can be surmised that tubular capillaries have been closed at one end with increasing fluorination temperature.

The SSA, calculated by the standard BET method, increases with fluorination temperature up to about $48 \mathrm{~m}^{2} \cdot \mathrm{g}^{-1}$ for the amorphous compound (Tab. 1). It then decreases for a fluorination temperature of 350 ${ }^{\circ} \mathrm{C}$. Such high value of SSA is unusual for fluoride compounds (SSA of crystalline $\mathrm{FeF}_{3}$ lower than 7 $\mathrm{m}^{2} \cdot \mathrm{g}^{-1}$ [21]) and is only obtained by solution nanostructuration [7]. The origin of the value of SSA is then totally different in our case. Here, SSA is due to pore formation into a micrometric texture, whereas for classical nanostructured fluorides, SSA is due to surface development of dense nanoparticles. Such differences on texture should act on lithium diffusion process during electrochemistry. In the case of nanostructures materials, lithium will act directly with each nanoparticle surface, whereas with porous micrometric particles, lithium will have to diffuse into the porosity.

Pore size distribution is the highest at about $3.5 \mathrm{~nm}$ for the compound fluorinated at $150{ }^{\circ} \mathrm{C}$. The size is practically the same for the sample synthesized at $200{ }^{\circ} \mathrm{C}$ but the mesoporous porous volume is twice as much. Two mesopore size distributions are present for the sample fluorinated at $350{ }^{\circ} \mathrm{C}$ : the one centered at $3.5 \mathrm{~nm}$ and other larger centered at 15 $\mathrm{nm}$ which consequently increases the pore mesopore volume up to $0.106 \mathrm{~cm}^{3} \cdot \mathrm{g}^{-1}$. The mesoporous texture is connected to a macroporous texture of lower pore volume. The macropore volume increases with the fluorination temperature because of the pore collapse with improvement of crystallization.

It is to note that the acetylene black -fluorinated sample mixture, ground for electrochemical purpose has also been analyzed by nitrogen adsorption isotherm. The SSA obtained is the weighted average of the SSA of each component of the mixture. The conditions applied for grinding can be concluded not to modify the texture of the sample and only favor a good dispersion of conductive carbon into insulating fluoride.

\begin{tabular}{|l|l|l|l|}
\hline Fluorination temperature & $150{ }^{\circ} \mathrm{C}$ & $200{ }^{\circ} \mathrm{C}$ & $300{ }^{\circ} \mathrm{C}$ \\
\hline $\mathrm{SSA}\left(\mathrm{m}^{2} \cdot \mathrm{g}^{-1}\right)$ & 13.3 & 48.0 & 32.1 \\
\hline $\mathrm{V}_{\text {micro }}\left(\mathrm{cm}^{3} \cdot \mathrm{g}^{-1}\right)$ & 0.000 & 0.002 & 0.001 \\
\hline $\mathrm{V}_{\text {meso }}\left(\mathrm{cm}^{3} \cdot \mathrm{g}^{-1}\right)$ & 0.030 & 0.060 & 0.106 \\
\hline $\mathrm{V}_{\text {macro }}\left(\mathrm{cm}^{3} \cdot \mathrm{g}^{-1}\right)$ & 0.009 & 0.014 & 0.032 \\
\hline Medium pore size $(\mathrm{nm})$ & 3.5 & 3.5 & $3.5 \& 15$ \\
\hline
\end{tabular}

Table 1. Adsorptive properties of $\mathrm{FeSi}_{2}$ fluorinated at different temperatures.

Fig. 1 shows the SEM micrograph of the raw material which appears as a dense material. At low fluorination temperature of $150^{\circ} \mathrm{C}$, this material is recovered by a foam. With fluorination temperature increase, some numerous well-defined slit pores are 
formed. SEM micrograph of the amorphous material presents a porous material with a high total pore volume in agreement with its unusually high SSA of $48 \mathrm{~m}^{2} \cdot \mathrm{g}^{-1}$. During the reaction, the formation and escape of a gas $\left(\mathrm{SiF}_{4}\right)$ from the precursor enlarged the surface area of $\mathrm{FeF}_{3}$. The pore size determined by SEM is in between 150 and $200 \mathrm{~nm}$, i.e. in the macropore range. This pore size does not clearly evolve as soon as fluoride is formed for temperature fluorination of $200{ }^{\circ} \mathrm{C}$. Macroporosity identified by SEM must be connected to a deeper mesoporosity characterized only by nitrogen isotherms, not visible by SEM because of the resolution of such a technique. This texture leads to predict a favorable lithium diffusion process.

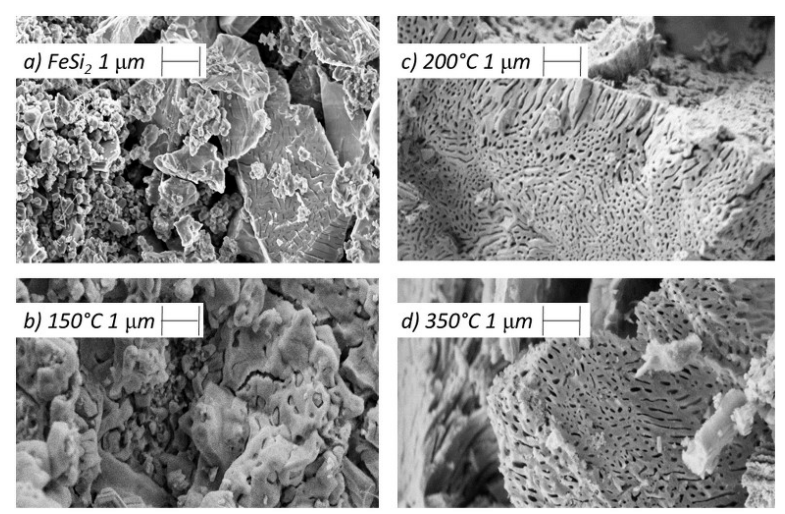

Figure 1. SEM micrographs of $\mathrm{FeSi}_{2}$, fluorinated at $150^{\circ} \mathrm{C}, 200^{\circ} \mathrm{C}$ and $350^{\circ} \mathrm{C}$

The $\mathrm{r}-\mathrm{FeF}_{3}$ phase used as cathode in secondary lithium batteries stands out from the other trifluoride iron phases by both its high and flat operating voltage [6]. Our electrochemical measurements confirm these facts. During the first discharge, a long flat plateau at $3.35 \mathrm{~V}$ is clearly observed, followed by an ill-defined process centered at about $3.0 \mathrm{~V}$. The electrochemical properties were measured by using galvanostatic discharge-charge experiments. To get the best electrochemical fingerprint both in terms of capacity and working potential, galvanostatic experiments were performed at 50 and $60{ }^{\circ} \mathrm{C}$ in order to facilitate conduction and diffusion processes. This implies to use an electrolyte stable at such high temperature of cycling in our operating conditions. $\mathrm{LiClO}_{4}$ PC $1 \mathrm{M}$ appears as a suitable electrolyte. The profiles of galvanostatic dischargecharge were then measured in the range of 2.5-4.3 $\mathrm{V}$. As in this voltage range carbon has no contribution in the specific capacity), the observed charge/discharge capacities can be directly and solely assigned to the electroactive iron fluoride. [22]

The specific capacity was about $250 \mathrm{mAh} \cdot \mathrm{g}^{-1}$, very close to the theoretical value of $\approx 240 \mathrm{mAh} \cdot \mathrm{g}^{-1}$ when considering the transfer of one electron as specified in eq. 1 :

$\mathrm{FeF}_{3}+\mathrm{e}^{-}+\mathrm{Li}^{+} \rightarrow \mathrm{LiFeF}_{3}$

Eq. 1

Besides, each of the two contributions involved roughly 0.5 electron. This behavior is in agreement with a transformation reported in literature operating initially through a two-phase region related with the $3.35 \mathrm{~V}$ voltage plateau up to $\mathrm{Li}_{0.5} \mathrm{FeF}_{3}$ and then through a solid-solution reaction centered at $3 \mathrm{~V}$ that involves insertion of lithium in $\mathrm{Li}_{0.5+\mathrm{x}} \mathrm{FeF}_{3}$ up to $\mathrm{LiFeF}_{3}$ [9],[23]. The reverse scan depicts a dissymmetric charge curve with two main electrochemical steps and leads to a coulombic efficiency of $88 \%$. Subsequent cycles kept the same shape even if a decrease of the capacity is observed. The step at higher potential is more impacted in particular during the first ten cycles, while the second one remained quite stable. From cycle 10 to cycle 20 , a stabilization of the capacity is achieved and interesting capacities about $100 \mathrm{mAh} . \mathrm{g}^{-1}$ are still available.

Fig. 2 and Fig. 3 evidenced the influence of the temperature on the electrochemical behavior of the $\mathrm{r}-\mathrm{FeF}_{3}$ material. Presented cycles are recorded at 60 ${ }^{\circ} \mathrm{C}$. The first discharge kept the same previous profile observed at $50{ }^{\circ} \mathrm{C}$ with the well-marked twostep insertion process. The major difference appears at lower potentials. Indeed, instead of a rapid potential decrease, characteristic of the end of the insertion step, a third process begins below $2.7 \mathrm{~V}$ highlighting the involvement of a partial conversion according to equation 2 :

$\mathrm{LiFeF}_{3}+2 \mathrm{e}^{-}+2 \mathrm{Li}^{+} \rightarrow \mathrm{Fe}+3 \mathrm{LiF} \quad$ Eq. 2

The restored capacity of $317 \mathrm{mAh} . \mathrm{g}^{-1}$ confirmed this statement as about $80 \mathrm{mAh} . \mathrm{g}^{-1}$ more were obtained with respect to the expected theoretical capacity for a $\mathrm{Li}$ uptake of $1 \mathrm{Li}$ per mole of $\mathrm{FeF}_{3}$. The temperature increase seems to favor conversion that happens at higher potential while no effect on insertion has been noticed.

Electrochemical cycling was performed on crystallized $\mathrm{FeF}_{3}$ over 100 cycles. Fig. 2 shows the voltage versus the capacity for selected 100 cycles. After 100 cycles, $\mathrm{r}_{-} \mathrm{FeF}_{3}$ shows $70 \%$ capacity loss and the discharge capacity was still as large as 95 mAh.g ${ }^{-1}$. There are few examples of electrochemical cycling in a short operating voltage $(2.5-4.3 \mathrm{~V})$ in the literature on $\mathrm{r}-\mathrm{FeF}_{3}$, but for example, recently J. H. Tan et al. have shown a first discharge capacity of about $115 \mathrm{mAh}^{-1} \mathrm{~g}^{-1}$ and after 100 cycles a capacity of $70 \mathrm{mAh} \cdot \mathrm{g}^{-1}$ [24]. The loss of capacity is higher in our case, but for the first discharge and for the $100^{\text {th }}$ cycle, the delivered capacity were obviously higher. This large difference of capacity on a same compound can be explained by the difference in the porosity, induced by the liberation of $\mathrm{SiF}_{4}$ during fluorination, which can support the lithium diffusion. Indeed, some 
recent works have studied the impact of the specific surface area of $\mathrm{FeF}_{3}$ on its electrochemical properties. For example, R. Ma et al. have embedded a $\mathrm{r}-\mathrm{FeF}_{3}$ of specific surface area of 6.9 $\mathrm{m}^{2} \cdot \mathrm{g}^{-1}$ into a carbon replica and a consecutive surface area of $204.7 \mathrm{~m}^{2} \cdot \mathrm{g}^{-1}$ of the mixture: an increase of more than $90 \%$ of both discharge and charge capacities were registered. It was explained as a buffering effect of the carbon matrix which plays an important role in interconnecting the $\mathrm{FeF}_{3}$ particles as well as accommodating the volume change during the electrochemical reaction [21]. These experimental data together with ours seem to indicate that the high specific surface area and the porous structure contribute to facilitate the lithium insertion and improve the electrochemical properties.

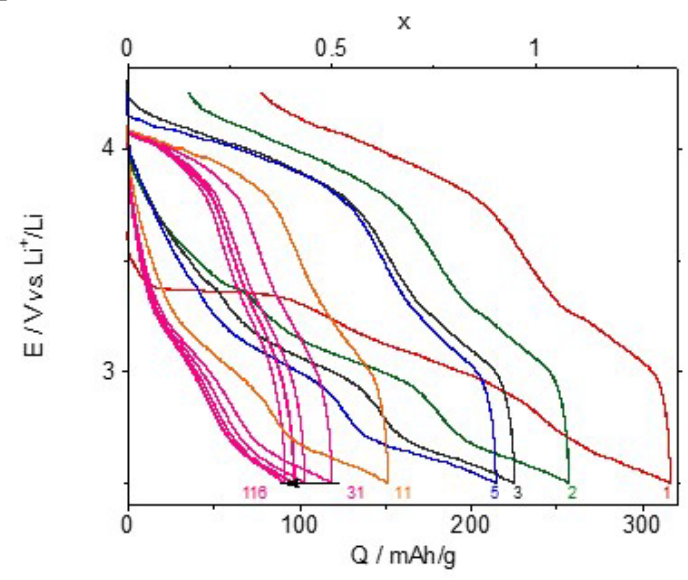

Figure 2. Charge/discharge cycles of a Li/crystallized r$\mathrm{FeF}_{3}$ cell obtained at $60^{\circ} \mathrm{C}$

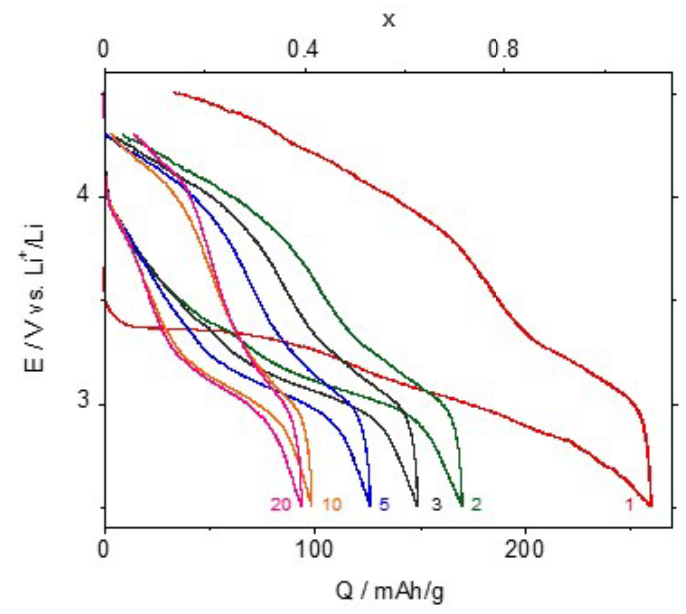

Figure 3. Charge/discharge cycles of a Li/crystallized r$\mathrm{FeF}_{3}$ cell obtained at $50^{\circ} \mathrm{C}$

\section{CONCLUSION}

Whereas most of the electrochemical studies on $\mathrm{FeF}_{3}$ as cathode material in secondary lithium battery focus on HTB hydrated phase, this work focuses on the potentiality of the rhombohedral phase. The known low performances of this phase result from its high temperature synthesis, which leads to huge crystalline insulating particles. A new synthesis process has been developed in order to form the rhombohedral phase at low temperature, i.e. from $260{ }^{\circ} \mathrm{C}$ by applying pure fluorine gas on iron disilicide. Iron disilicide has also been chosen for its release during fluorination of $\mathrm{SiF}_{4}$ which is a known pore-forming gas. In this way, a mesoporous texture centered at $3.5 \mathrm{~nm}$ connected with a macroporous one nearby $150 \mathrm{~nm}$ is formed as soon as the fluorination process starts. Rhombohedral phases have good ability as cathode material in lithium battery with a lower hysteresis and a lower capacity loss upon cycle for amorphous phase and a higher capacity for rhombohedral one.

This work opens the way to the use of many other precursors usable under pure fluorine gas to get other pore size distribution. The nature of the carbon (graphene for example) used during mecanochemistry can also be tuned in order to improve the electrochemical performances of the present materials.

\section{REFERENCES}

1. Tarascon, J.M., \& Armand, M. (2008). Building Better Batteries. Nature 451, 652-657.

2. Bruce, P.G., Scrosati, B. \& Tarascon, J.-M. (2008). Nanomaterials for Rechargeable Lithium Batteries. Angewandte Chemie International Edition 47(16), 2930-2946.

3. Goodenough, J.B. \& Kim., Y. (2010). Challenges for rechargeable Li batteries. Chem. Mater. 22 587-603.

4. Arai, H., Okada, S., Sakurai, Y. \& Yamaki, J.-i. (1997). Cathode performance and voltage estimation of metal trihalides. J. Power Sources 68(2), 716-719.

5. Bervas, M., Mansour, A.N., Yoon, W.-S., AlSharab, J.F., Badway, F., Cosandey, F., Klein, L.C. \& Amatucci, G.G. (2006). Investigation of the Lithiation and Delithiation Conversion Mechanisms of Bismuth Fluoride Nanocomposites. J. Electrochem. Soc. 153(4), A799-A808.

6. Badway, F., Pereira, N., Cosandey, F. \& Amatucci, G.G. (2003). Carbon-Metal Fluoride Nanocomposites: Structure and Electrochemistry 
of FeF 3 : C. J. Electrochem. Soc. 150(9), A1209A1218.

7. Li, C., Gu, L., Tong, J., Tsukimoto, S. \& Maier, J. (2011). A Mesoporous Iron-Based Fluoride Cathode of Tunnel Structure for Rechargeable Lithium Batteries. Adv. Functional Mater. 21(8), 1391-1397.

8. Doe, R.E., Persson, K.A., Meng, Y.S .\& Ceder, G. (2008). First-Principles Investigation of the $\mathrm{Li}-\mathrm{Fe}-\mathrm{F}$ Phase Diagram and Equilibrium and Nonequilibrium Conversion Reactions of Iron Fluorides with Lithium. Chem. Mater. 20(16), 5274-5283.

9. Conte, D. \& Pinna, N. (2014). A review on the application of iron(III) fluorides as positive electrodes for secondary cells. Mater. Renew. Sustain. Energy 3(4), 1-22.

10. Ferey, G., Leblanc, M., De Pape, R. \& Pannetier, J., (1985). Competing Spin Interactions and Frustration Effects in Fluorides, in Inorganic Solid Fluorides, P. Hagenmuller, Editor Academic Press, pp 395-414.

11. Louvain, N., Fakhry, A., Bonnet, P., El-Ghozzi, M., Guerin, K., Sougrati, M.-T., Jumas, J.-C. \& Willmann, P. (2013). One-shot versus stepwise gas-solid synthesis of iron trifluoride: investigation of pure molecular $F_{2}$ fluorination of chloride precursors. Cryst. Eng. Comm. 15(18), 36643671 .

12. Leblanc, M., Ferey, G., Chevallier, P., Calage, Y. \& De Pape, R. (1983). Hexagonal tungsten bronzetype FeIII fluoride: $\left(\mathrm{H}_{2} \mathrm{O}\right) 0.33 \mathrm{FeF}_{3}$; crystal structure, magnetic properties, dehydration to a new form of iron trifluoride. J. Solid State Chem. 47(1), 53-58.

13. Ferey, G., Leblanc, M., De Pape, R., Passaret, M. \& Bothorel-Razazi, M.P. (1975). Cristallisation par voie hydrothermale des fluorures $\mathrm{FeF}_{3} ; \mathrm{FeF}_{3}$, $\mathrm{H}_{2} \mathrm{O} ; \mathrm{FeF}_{3}, 3 \mathrm{H}_{2} \mathrm{O}$; et $\mathrm{NH}_{4} \mathrm{FeF}_{4}$. J. Crystal Growth 29(2), 209-211.

14. Kim, S.-W., Seo, D.-H., Gwon, H., Kim, J. \& Kang, K. (2010). Fabrication of $\mathrm{FeF}_{3}$ Nanoflowers on CNT Branches and Their Application to High Power Lithium Rechargeable Batteries. Adv. Mater. 22(46), 5260-5264.

15. Li, C., Gu, L., Tong, J. \& Maier, J. (2011). Carbon Nanotube Wiring of Electrodes for High-Rate Lithium Batteries Using an Imidazolium-Based Ionic Liquid Precursor as Dispersant and Binder:
A Case Study on Iron Fluoride Nanoparticles. ACS Nano 5(4), 2930-2938.

16. Li, C., Yin, C., Mu, X. \& Maier, J. (2013). TopDown Synthesis of Open Framework Fluoride for Lithium and Sodium Batteries. Chem. Mater. 25(6), 962-969.

17. Tan, J., Liu, L., Hu, H., Yang, Z., Guo, H., Wei, Q., Yi, X., Yan, Z., Zhou, Q., Huang, Z., Shu, H., Yang, X. \& Wang, X. (2014). Iron fluoride with excellent cycle performance synthesized by solvothermal method as cathodes for lithium ion batteries. J. Power Sources 251, 75-84.

18. Myung, S.-T., Sakurada, S., Yashiro, H. \& Sun, Y.-K. (2013). Iron trifluoride synthesized via evaporation method and its application to rechargeable lithium batteries. J. Power Sources 223, 1-8.

19. Greneche, J.M., Varret, F., Leblanc, M. \& Ferey, G. (1987). Mössbauer spectroscopy study of crystallization of amorphous iron (III) fluorides: Influence of experimental conditions. Solid State Comm. 61(12), 813-816.

20. Leofanti, G., Padovan, M., Tozzola, G. \& Venturelli, B. (1998). Surface area and pore texture of catalysts. Catalysis Today 41, 207-219.

21. Ma, R., Wang, M., Tao, P., Wang, Y., Cao, C., Shan, G., Yang, S., Xi, L., Chung, J.C.Y. \& Lu, Z. (2013). Fabrication of $\mathrm{FeF}_{3}$ nanocrystals dispersed into a porous carbon matrix as a high performance cathode material for lithium ion batteries. J. Mater. Chem. A 1(47), 15060-15067.

22. Collins, J., Gourdin, G., Foster, M. \& Qu, D. (2015). Carbon surface functionalities and SEI formation during $\mathrm{Li}$ intercalation. Carbon 92, 193244.

23. Yamakawa, N., Jiang, M., Key, B. \& Grey, C.P. (2009). Identifying the Local Structures Formed during Lithiation of the Conversion Material, Iron Fluoride, in a Li Ion Battery: A Solid-State NMR, X-ray Diffraction, and Pair Distribution Function Analysis Study. J. Am. Chem. Soc. 131(30), 10525-10536.

24. Tan, H.J., Smith, H.L., Kim, L., Harding, T.K., Jones, S.C. \& Fultz, B. (2014). Electrochemical Cycling and Lithium Insertion in Nanostructured $\mathrm{FeF}_{3}$ Cathodes. J. Electrochem. Soc. 161(3), A445-A449. 